\title{
Iranian National Curriculum and the Pre-university English Textbook: The Degree of Compatibility of Objectives
}

\author{
Leila Mahmoudi \\ Faculty of Persian Literature and Foreign Languages, \\ Allameh Tabatabaee University of Tehran, Iran \\ E-mail: leilamahmoudi1979@yahoo.com \\ Kamariah Abu Bakar \\ Institute for Mathematical Research, \\ Universiti Putra Malaysia (UPM), Malaysia
}

Received: 02-02- 2013

doi:10.7575/aiac.ijels.v.2n.2p.4
Accepted: 17-03-2013

Published: $30-04-2014$

URL: http://dx.doi.org/10.7575/aiac.ijels.v.2n.2p.4

\begin{abstract}
Textbooks are one of the important teaching materials in language teaching and a common resource for any teacher in helping students to learn English. Apart from being a learning tool, textbooks are considered as an important medium to realize curriculum goals and objectives. The purpose of this study is to investigate the amount of compatibility of the pre-university English textbook, which is prescribed by the ministry of education, with Iranian National Curriculum (INC) in terms of objectives and content of teaching. To this end, two instruments were used: A textbook evaluation checklist proposed by Ghorbani (2011), and the Iranian National Curriculum. The findings of the study revealed that the textbook was not in line with the curriculum in terms of objectives and content of teaching.
\end{abstract}

Key words: Pre-university textbook, Iranian National Curriculum (INC), English teaching.

\section{Introduction}

Textbooks provide the core materials for a course in any educational system. However, the degree of utilizing the textbooks may differ in different educational systems since teachers may or may not be allowed to choose their own textbook. In other words, teachers are relegated to "textbook slaves" (Lam, 1994) in that they have no other choice but to teach a dictated textbook. Iran's educational system is one of those which make the teachers slave of the prescribed textbooks. It is the textbooks which define the objectives of language teaching and learning and the skills being taught. On the other hand, there is a conviction among some scholars (e.g., Flanders, 1994; Tholey, 1994) that textbooks represent the curriculum. In other words, the objectives and guidelines of national curriculum ought to be viewed as a blueprint for what should or should not be done in the classrooms. According to them, the textbooks should be designed based on the objectives stipulated in the national curriculum.

When it comes to the review of existing studies on the textbooks used in Iran's educational system, it is revealed that the textbooks have been investigated from a variety of perspectives. Aliakbari (2004) examined high-school English textbooks in terms of the resourcefulness of the materials for developing intercultural competence on the part of the students. The findings of the study indicated that the textbooks were not adequate enough to enhance the intercultural competence of the students. Razmjoo (2007) conducted his study to find out the extent to which the textbooks represented Communicative Language Teaching (CLT) principles. He analyzed the content of the textbooks of high schools and private institutes (The Interchange Series).The analysis of the data indicated that there was a significance difference between the two types of textbooks' domains. The high school textbooks were mostly based on reading and grammar. However, the textbooks taught in the private institutes provided an equal balance among all the skills and components of the language. With regard to the gender representation, Hosseini Fatemi, Pishghadam and Heidarian (2011) found out that there was a considerable imbalance in the representation of males and females; the textbooks had a lower portrayal of women, and were evidently tilted in favor of male domination and female subordination, confirming the traditional view of gender stereotyping.

Overall, the above reviews show a gap in the literature in regard to the degree of go-togetherness between the objectives of the Iranian National Curriculum and the high-school textbooks in general and the pre-university textbook in particular.. Bearing this loophole in mind, the following research question is posed to guide the study: 


\section{Methodology}

In order to find out the degree of compatibility between the objectives of the pre-university English textbook with those of the curriculum, firstly, the objectives and goals of the curriculum were used as benchmarks for comparison and secondly, the textbook was analyzed by three PhD candidates in TESL based on a checklist proposed by Ghorbani (2011). In his checklist, Ghorbani proposed seven categories to be considered for evaluation of an English textbook: practical considerations, language skills, exercises/activities, pedagogic analysis, appropriateness, supplementary materials, and general impression. According to Cunningswoth (1995), the first thing which should be taken into consideration in evaluating a textbook is to identify our priorities and then choose the most important criteria for the analysis. Therefore, in this study six categories (i.e., language skills, exercises/activities, pedagogic analysis, appropriateness, supplementary materials, \& general impression) from among seven categories were chosen to be used for the analysis of the pre-university textbook. The first part of the checklist (i.e., practical considerations which were about the textbook's physical appearance, cost, etc.) was excluded from the analysis. Last but not least, the criteria of the checklist were numerically rated: 0 (poor), 1 (satisfactory) and 2 (good). Seven subheadings: A. Language Skills, B. Exercises and Activities, C. Pedagogic Analysis, D. Appropriateness, E. Supplementary Materials, and F. General Impressions were included in the checklist.

\section{Findings of the Study}

\subsection{Textbook Analysis}

\subsubsection{Language Skills}

The pre-university textbook was first rated in terms of its language skills as provided in Table 1 below.

Table 1. Language Skills Presented in the Pre-university Textbook

$$
\text { A: Skills }
$$

Scores

1. Are the skills presented in the textbook appropriate to the course?

2. Does the textbook provide learner with adequate guidance as they are acquiring these skills?

3. Do the skills that are presented in the textbook include a wide range of cognitive 0 skills that will be challenging to learners?

4. Is the balance between listening, speaking, reading, and writing skills development in 0 the textbook appropriate to the particular learner and learning situation?

5. Is the skills integration given sufficient attention?

6. Is the development of discourse and fluency skills given sufficient attention?

The raters rated the textbook as "satisfactory" when it came to the appropriateness of the textbook to the course and the adequacy of the guidance provided by the textbook to the learners to acquire the language skills. However, their evaluation of the textbook was "poor" when they rated the textbook's degree of coverage of cognitive skills, the balance between the language skills, the integration of the skills, as well as the adequacy of the textbook in developing discourse and fluency skills.

\subsection{Exercises and Activities}

The three raters ranked the pre-university textbook in terms of exercises and activities as presented below in Table 2 .

Table 2. Exercises and Activities of the Pre-university Textbook

B: Exercises and Activities Scores

7. Do the exercises and activities in the textbook promote learners' language 0 development?

8. Is there a balance between controlled and free exercises?

9. Do the exercises and activities reinforce what students have already learned and represent a progression from simple to more complex?

10. Are the exercises and activities varied in format so that they will continually motivate and challenge learners?

11. Are these activities for communicative interaction and the development of communicative strategies?

12. Are new structures presented systematically and in a meaningful context? 1

13. Is the meaning of new vocabulary presented in context?

14. Is there sufficient work recognition and production of individual sounds for pronunciation practice?

15. Is there sufficient work on recognition and production of stress patterns and intonation?

16. Is there a summary of new and reviewed grammar?

17. In general are the activities in the book neither too difficult nor too easy for the learners? 
As Table 3 indicates the three raters held a positive view about the level of difficulty of language activities as well as the contextualized presentation of the new vocabulary items in the pre-university textbook, and rated the two items on the checklist as "good." However, the textbook's quality in terms of its having the balance between controlled and free exercises, the procedural progression of language activities from simple to more difficult, systematic presentation of the new structures, and the summary of new and reviewed grammar was rated as "satisfactory." Those qualities of the textbook which were not favored by the raters and was rated as "poor" were the inefficacy of the textbook's exercises and activities in promoting learners' language development, the poor motivational and challenging capacity of language activities, the inadequacy of its language activities to develop learners' communicative competence, as well as its lack of any activities related to supra-segmental aspects of language.

\subsubsection{Pedagogic Analysis}

The textbook was rated by the raters with respect to some pedagogical benchmarks as indicated in Table 3 .

Table 3. Pedagogical Analysis of the Pre-university Textbook

$$
\text { C: Pedagogic Analysis }
$$

Scores

18. Is the book methodologically in line with current worldwide theories and practice of language learning?

19. Does the book contain adequate formal learner achievement tests?

0

0

20. Is the book enabling learners to use English outside the classroom situation?

21 . Is the book sufficiently challenging to learners?

0

1

22. Are there mechanisms for giving regular feedback to learners?

0

23. Are new items reviewed and recycled throughout the book?

0

24. Does the book match the syllabus of the school to a sufficient extent? Is the time allowance indicated appropriate?

Unlike the challenging capacity of the textbook's language activities which the raters rated as 'satisfactory', the other items of the section were rated as "poor." The rating practice revealed that from the perspective of the raters: 1 . the textbook was barely in line with the current trends of learning theories and practices; 2 . the textbook was hardly capable of preparing the language learners to cope with real-life situations; 3 . There hardly existed any mechanism to provide learners with regular feedback 4 . The new items were seldom reviewed and recycled throughout the textbook; 5 . The textbook did not match the curriculum to a sufficient extent as well.

\subsubsection{Appropriateness}

The textbook's appropriateness in terms of its being up-to-date and attending to the short-term and long-term needs of the learners was rated as 'poor' whereas the other qualities which the raters were almost satisfied and fairly positive about were: 1. Their general impression of the textbook's content, instructions, and language focus/ activities. 2. The compatibility of the textbook with the objectives of the learner; 3 . The facilitating role of the textbook for interactive learning; 4. The socio-cultural appropriateness of the textbook; 5 . The well-gradedness of the input; 6 . The ageappropriateness of the textbook, and 7. The textbook's relevance to real-life practices.

Table 4. The Appropriateness of the Pre-university Textbook

$$
\text { D: Appropriateness }
$$

Scores

33. Are the materials, instructions, language focus, and activities in general 1 appropriate for the learners?

34. Will the textbook meet the long and short term goals specific to the learners?

35. Does the material match learner objectives?

36. Does the material facilitate interactive learning?

1

37. Is the material socio-culturally appropriate?

38. Is the material up-to-date?

1

39. Are vocabulary and comprehensible input levels well-graded?

40. Is the material age-appropriate?

41. Is the material relevant to real life?

\subsubsection{Supplementary Materials}

The Pre-university textbook did not have any accompanying teacher's book or a student's workbook. It only had an audio $\mathrm{CD}$ for reading texts. 
Table 5. Supplementary Materials Considerations

F: Supplementary Materials

Scores

42. Is a teacher's book available and does it give useful and complete guidance, 0 along with alternative activities?

43. Is a workbook available and does it contain appropriate supplementary activities?

44. Are audio-visual aids accompanied? and are they of good quality?

1

\subsubsection{General Impression}

Table 6. General Impression of the Textbook

$$
\mathrm{F} \text { : General Impression }
$$

Scores

45. Does it have clear objectives \& instructions?

46. Does it include reasonable balance \& range in skills and activities?

47. Does it motivate learners by pleasurable activities or arouse learner interest?

48. Does it provide a variety of Communicative activities? Does it promote the use of information/opinion gap?

49. Is the cultural tone of the book overall appropriate for use in the setting?

50. Does the book encourage learners to assume responsibility for their own learning?

The raters' impressionistic view about the evaluation criteria of the textbook, as illustrated in Table 6, was obviously varying between the extreme scores of 0 and 2. Whereas the raters assigned the maximum score of 2 to the textbook's presentation of clear objectives/instructions and to its appropriateness of the cultural tone in the socio-cultural context of Iran, the textbook got the lowest score for other rating criteria: 1. the existence of a reasonable balance between the skills and language activities of the textbook; 2. motivational and interest-arousing features of the textbook; 3 . The diversity of the communicative activities of the textbook, and 4. The suitability of the textbook to encourage responsibility and life-long learning on the part of the learners."? 3.2 Scrutiny of the National Curriculum

In order to find out as to whether the objectives of the National Curriculum were reflected in the content of the preuniversity textbook and the INUEE, the curriculum was scrutinized. The principal objectives and recommendations of the curriculum are enumerated as follows.

1. The enterprise of language teaching ought to go beyond the influence of a bunch of limiting theories, approaches and methods, and aim at preparing the ground for boosting the national culture and fostering the social values. Given the crucial role of education in growth and salvation of human beings, any necessary step must be taken in the direction of materialization of the lofty goals of education.

2. Mainstream language education theories emphasize the development of communicative competence on the part of learners. According to the well-established tenets of those theories, language learners need to focus on and to become competent and proficient enough in all of the four receptive and productive language skills (i.e., listening, reading, speaking, and writing).

3. Education of the foreign language officially starts at the first grade of Guidance school (junior high school) and is intended to concurrently develop the four language skills as well as communicative abilities in the framework of the general educational blueprint. During the senior high school, the learners are expected to be able to read the intermediate-level texts and comprehend them. In addition, their writing ability is expected to be developed to the level of writing short essays. In conjunction with such prospects and purposes, the learners are thought to be proficient enough to make use of intermediate-level materials and be capable of communicating in a foreign language. The foreign languages could be English, French, German, and any other language approved by the supreme council of Ministry of Education.

4. The overall orientation of the country's foreign language education should be towards development of active communicative abilities and fostering learner-centeredness. In the preliminary stages of foreign language education, the content of the materials should be focused on domestic issues and fulfilling learners' essential needs such as personal hygiene and health, everyday life, etc and in the higher levels it is to be centered on issues related to culture, science, economics, politics, etc. It is also worthwhile to note that at the end of senior high school the graduates are expected to have developed the ability to read and comprehend simple specialized texts. 


\section{Discussion and Conclusion}

Comparison of the findings of document analysis (i.e., National Curriculum, and the pre-university textbook) revealed that the objectives of the National Curriculum were barely reflected in the content of the pre-university textbook. For instance, contrary to the directions of the curriculum, culture seemed to be a neglected essential in the textbook. Whereas the curriculum stressed the importance of raising the awareness of the learners towards the target culture, the textbook does hardly contain anything about the target culture. Aliakbari's (2004) study suggested a similar finding. As for the focus of the textbook, it was revealed that the focus of the textbook was not on the same language areas and skills as the curriculum suggested. Reading skill, vocabulary, and grammar were the only language skills and components contained in the textbook while in the curriculum the emphasis was on teaching the four language skills. In the curriculum it was mentioned that there should be some kind of balance between language skills.

As far as the teaching method was concerned, it was revealed that the pre-university textbook did not follow the curriculum in terms of teaching method as well. Indeed, teaching English communicatively was one of the chief aims of the curriculum which was not reflected in the textbook at all. In fact, analyzing the textbook showed that it was absolutely structure-based which was not mentioned in the curriculum. For instance, in some parts of the textbook students were encouraged to use bilingual dictionary to find the unknown vocabulary and the focus of the textbook was on teaching reading, vocabulary, and grammar only. In conclusion, the study found out that the compatibility between the objectives of the curriculum and the prescribed textbook was negligible and it seemed that the textbook was not designed based on the national curriculum's objectives.

\section{References}

Aliakbari, M. (2004). The place of culture in the Iranian ELT textbooks in high school level.Paper presented at the 9th Pan-Pacific Association of Applied Linguistics Conference. Namseoul University, Korea.

Birjandy, P., Annabi Sarab, M. \& Samimi, D. (2004). Learning to read English for pre-university students. Tehran: Textbook Publishing Company of Iran

Cunningsworth, A. (1995). Choosing your coursebook. Oxford: Heinemann Educational Books.

Flanders, J.R. (1994). Textbooks, teachers, and the SIMS test. Journal for Research in Mathematics Education, 25, 260278.

Ghorbani, M. R. (2011). Quantification and graphic representation of EFL textbook evaluation results. Theory and Practice in Language Studies, 1 (5)

Hosseini Fatemi, A., Pishghadam, R., \& Heidarian, Z. (2011). Gender delineation in high school and pre-university ELT textbooks: A criterion-oriented approach to text analysis. The Iranian EFL Journal, 7 (3), 32-47. Retrieved http://www.iranian-efl-journal.com/

Iranian National Curriculum (2010). Ministry of education. Iran, Tehran.

Lam, H. P. (1994). Methodology washback- an insider's view. In D. Nunan, R. Berry, \& V. Berry (Eds.), Bringing about change in language education: (pp. 83-99). Hong Kong: University of Hong Kong.

Razmjoo, S. A. (2007). High schools or private institutes textbooks? Which fulfill communicative language teaching principles in the Iranian context? Asian EFL Journal, 9(4), 126-140. Retrieved from http://www.asian-efl-journal.com/

Tholey, M. (1994). The quality of textbooks: A preliminary to successful curriculum implementation. Book of summaries of the first European Conference on Curriculum, University of Twenty, Netherlands 